\title{
El proceso de desapalancamiento externo de la economía española: un largo camino por recorrer*
}

\author{
Judit Montoriol Garriga \\ CaixaBank Research
}

\section{Resumen}

Uno de los principales desequilibrios macroeconómicos de la economía española es el elevado endeudamiento, tanto público como privado, y además, una notable proporción de este se encuentra en manos extranjeras. A pesar de que desde 2012 el endeudamiento total de la economía ha empezado a descender, este sigue siendo muy elevado y la dependencia de la financiación externa apenas se ha reducido. El presente artículo realiza un análisis de la evolución del endeudamiento de la economía española entre los años 2000 y 2016 por sectores institucionales, prestando particular atención al papel primordial del sector bancario y a su dependencia de la financiación externa. La reducción de la deuda externa (pública y privada) hacia niveles sostenibles es imprescindible para mejorar la capacidad de crecimiento y reducir la vulnerabilidad externa de la economía española.

Palabras clave: deuda privada, deuda pública, deuda externa, desapalancamiento.

Clasificación JEL: G21.

\begin{abstract}
One of the main macroeconomic imbalances of the Spanish economy is the high indebtedness, both public and private, and in addition, a notable proportion of this is in foreign hands. Despite the fact that since 2012 the total debt of the economy has begun to fall, it is still very high and dependence on external financing has barely been reduced. This article analyzes the evolution of debt of the Spanish economy between 2000 and 2016 by institutional sectors, paying particular attention to the central role of the banking sector and its dependence on external financing. The reduction of external debt (public and private) to sustainable levels is essential to improve growth capacity and reduce the external vulnerability of the Spanish economy.
\end{abstract}

Keywords: private debt, public debt, external debt, deleveraging.

JEL classification: $G 21$.

\section{Introducción}

Han pasado ya casi cuatro años desde que empezó la recuperación de la economía española en el tercer trimestre de 2013 y, afortunadamente, ya se empieza a ver la luz al final del túnel. El PIB ha recuperado el nivel máximo alcanzado antes de la crisis y la creación de empleo avanza a buen ritmo. Sin embargo, todavía limita el

* Todas las opiniones expresadas en el presente artículo son propias de la autora y no necesariamente reflejan las opiniones de CaixaBank Research. 
desempeño económico uno de los principales legados del anterior ciclo expansivo: el elevado endeudamiento.

La entrada en circulación del euro marcó el comienzo de un periodo expansivo caracterizado por un fuerte crecimiento del endeudamiento de la economía española. Si en el año 2000 la deuda del total de la economía representaba el 177 por 100 del PIB, en el año 2012, cuando alcanzó el valor máximo, esta se había prácticamente doblado (302 por 100 del PIB) ${ }^{1}$. En este periodo, el ahorro doméstico era insuficiente para cubrir las necesidades de financiación del país, de modo que se recurrió a la financiación exterior. Ello se vio reflejado en una posición negativa de la balanza financiera año tras año y en un aumento del nivel de deuda externa acumulada. El sector bancario, como principal intermediario financiero de la economía española, desempeñó un papel central en la canalización del ahorro externo para cubrir las necesidades de financiación domésticas.

A partir del año 2010, el sector privado empezó un profundo proceso de desendeudamiento, aunque la deuda total de la economía no disminuyó al mismo ritmo debido al crecimiento de la deuda pública en estos últimos años. Estas dinámicas han tenido su reflejo en la evolución de los balances bancarios: el nivel de endeudamiento de la propia banca también se ha reducido significativamente desde el máximo alcanzado en 2012, especialmente su dependencia de la financiación externa. Con todo, la dependencia de la financiación externa sigue siendo elevada aunque gran parte de estos flujos se canalizan a través del Banco de España, reflejo de las políticas monetarias expansivas del BCE.

La dependencia de la financiación externa es una fuente de vulnerabilidad de la economía puesto que está mucho más expuesta a los cambios de expectativas de los inversores internacionales. La literatura académica ha documentado ampliamente que los flujos de crédito trasfronterizos tienden a crecer mucho más rápido durante la fase expansiva del ciclo crediticio, de modo que los flujos de crédito internacionales son un factor determinante del crecimiento del crédito en la economía doméstica. Sin embargo, en la fase contractiva, estas entradas de capital acostumbran a cambiar de signo, generado una mayor caída del crédito².

En el presente artículo se analiza la evolución del endeudamiento de la economía española por sectores institucionales en el periodo 2000-2016, prestando particular atención a dos particularidades: el papel del sector bancario en la financiación de dicha deuda y el volumen de deuda en manos extranjeras. La sección 2 describe brevemente la fuente de datos y define ciertos aspectos metodológicos. La sección 3 analiza la evolución de la deuda por sectores institucionales y se presenta el cálculo de la deuda de las instituciones financieras ajustada para evitar la doble contabilización de deuda con otros sectores institucionales, con el fin de obtener una medida de la deuda agregada del total de la economía. La sección 4 se dedica a analizar el papel del sector

\footnotetext{
${ }^{1}$ En la sección 3 se detallan los aspectos metodológicos concernientes al cálculo de estas cifras (deuda ajustada).

2 Véase, por ejemplo, AVDJIEV et al. (2012) y BORIO et al. (2011).
} 
financiero en la financiación de la deuda privada y pública, así como la dependencia de la financiación exterior de cada sector institucional. La sección 5 analiza la evolución del balance financiero de las instituciones financieras, en concreto, las fuentes de financiación bancaria y su apelación a la financiación exterior. Finalmente, en la sección 6, se analiza la deuda externa y la posición de inversión internacional neta del total de la economía. La sección 7 concluye con unas breves reflexiones.

\section{Cuestiones previas: aspectos metodológicos y niveles de referencia}

Los datos analizados provienen de los balances financieros de los sectores institucionales de la economía española (hogares e instituciones sin fines de lucro al servicio de los hogares, sociedades no financieras, Administraciones públicas e instituciones financieras) de las cuentas financieras publicadas por el Banco de España. También se usa la cuenta del resto del mundo para analizar la deuda externa ${ }^{3}$.

Conviene empezar con tres precisiones metodológicas. En primer lugar, el análisis de la deuda por sectores institucionales se realiza en términos brutos. La deuda bruta se define como la suma de préstamos y valores representativos de deuda del pasivo en el balance financiero de cada sector institucional. No se tienen en cuenta los activos financieros disponibles para reducir dicha deuda puesto que el análisis se realiza a nivel de sector institucional y es posible que los activos y los pasivos no se encuentren en el balance del mismo agente. En segundo lugar, se hace referencia a la deuda consolidada y la no consolidada. La deuda no consolidada se refiere a la deuda total sin tener en cuenta el acreedor de dicha deuda. Deuda consolidada, por su parte, excluye la deuda que tiene como contrapartida un agente del mismo sector institucional. En tercer lugar, se hace referencia a la deuda externa, es decir, la deuda emitida por un sector residente cuyo agente de contrapartida es el resto del mundo.

Finalmente, para evaluar si el nivel de deuda es excesivo, es útil disponer de niveles de referencia. En este artículo, se usan los umbrales establecidos por la Comisión Europea en el mecanismo de control de los desequilibrios macroeconómicos (MIP, Macroeconomic Imbalance Procedure $)^{4}$. Sobrepasar estos umbrales no implica necesariamente que la deuda sea insostenible, sino que debe interpretarse como una señal de alerta y la necesidad de tomar medidas para corregir el desequilibrio en cuestión. En concreto, se hace referencia a 5 indicadores (de los 14 que componen el MIP) y sus respectivos umbrales:

- Deuda del sector privado (consolidada): 133 por 100 del PIB.

- Deuda del sector público: 60 por 100 del PIB.

\footnotetext{
${ }^{3}$ Además, se usan los datos de deuda externa del capítulo 7.9 de los Indicadores Económicos, también publicados por el Banco de España, y los datos de la Posición de inversión internacional neta del capítulo 7.6.

${ }^{4}$ Estos umbrales se determinan a partir del tercer cuartil de la distribución empírica anual de la eurozona para el periodo 1995-2007 (véase COMISIÓN EUROPEA, 2012).
} 
- Flujo de crédito al sector privado: 14 por 100 del PIB.

- Variación anual del total de pasivos del sector financiero: 16,5 por 100.

- Posición de inversión internacional neta: 35 por 100 del PIB.

\section{Evolución de la deuda por sectores institucionales}

Comenzando por el sector privado, resulta destacable que en el año 2000 la deuda bruta no consolidada de los hogares y las sociedades no financieras equivalía al 45,1 por 100 y al 73 por 100 del PIB, respectivamente (118,1 por 100 en agregado). La deuda privada consolidada, que excluye la deuda entre empresas, era inferior, del 102,5 por 100 del PIB. Comenzó, entonces, un rápido crecimiento de la deuda privada que ya en el año 2004 superó el umbral del 133 por 100 del PIB establecido en el MIP. De este modo, la deuda privada de la economía española alcanzó su nivel máximo en el año 2010, cuando se situó en el 202,7 por 100 del PIB en términos consolidados. La deuda privada no consolidada, por su parte, alcanzó el 218 por 100 del PIB, de los que 15 puntos porcentuales (p. p.) correspondían a deuda de sociedades no financieras con este mismo sector institucional como contrapartida (Gráfico 1).

\section{GRÁFICO 1}

DEUDA PRIVADA Y UMBRAL DEL MIP

(En \% del PIB)

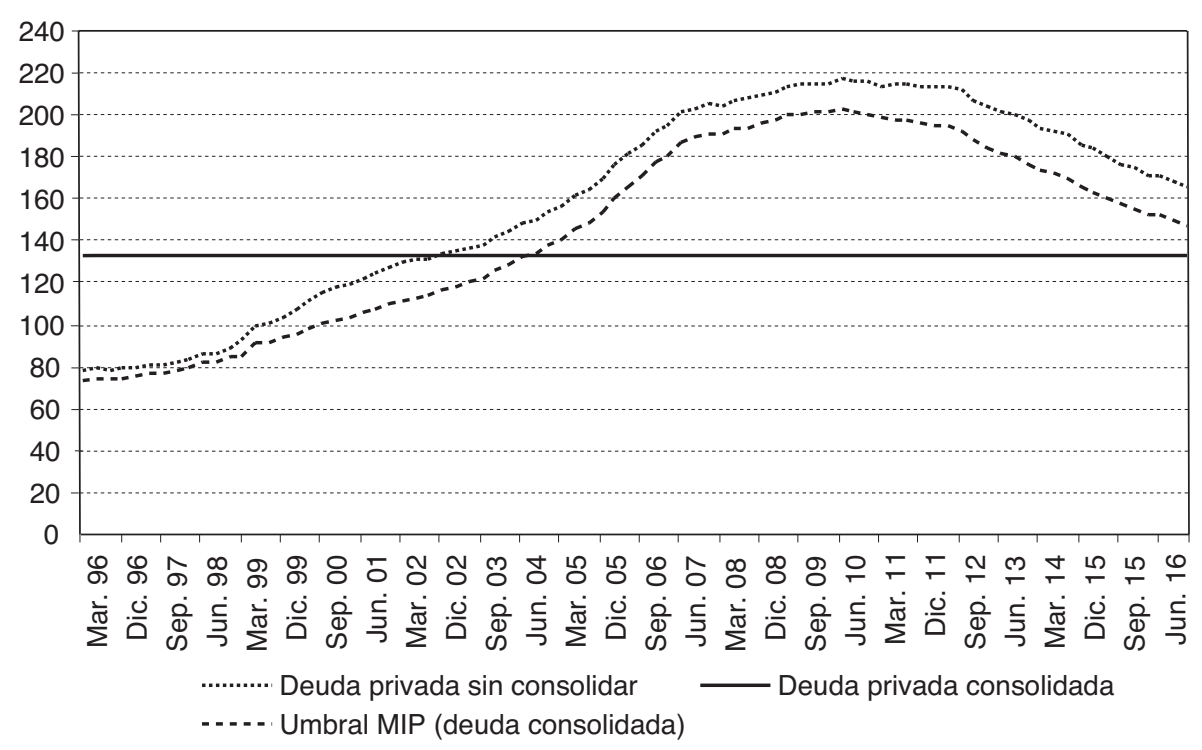

FUENTE: Banco de España y Comisión Europea. 
Los datos más recientes, correspondientes al cuarto trimestre de 2016 (en adelante, para abreviar se utiliza la notación 4T 2016), muestran que la deuda privada consolidada se ha reducido hasta el 147,3 por 100 del PIB, es decir, 55,4 p. p. por debajo del máximo que llegó a alcanzar. Por tanto, después de 6 años desendeudándose, el sector privado estaría cerca de niveles más sostenibles. La comparativa con otros países europeos muestra que España es el país que más ha reducido su endeudamiento privado en los últimos años, a excepción de Luxemburgo (-67 p. p.). Le siguen Portugal y Reino Unido, con una reducción de la deuda privada consolidada de 30 y 28 p. p. desde sus respectivos niveles máximos (Gráfico 2).

Dentro del sector privado, la evolución de los hogares y las empresas españolas, sin embargo, es diferenciada. Por un lado, las empresas se han desendeudado de forma acelerada. En efecto, si tomamos la eurozona como referencia, las sociedades no financieras españolas, en agregado, alcanzaron el nivel de deuda de sus homólogas europeas en el 2T 2016. Los hogares, en cambio, se están desendeudando algo más lentamente debido a que la mayor parte de su deuda es a largo plazo y a que tienen menos mecanismos a su disposición para desendeudarse.

Aunque la deuda de los hogares españoles todavía se sitúa 6 p. p. por encima de la de los hogares europeos, si se mantiene el ritmo de reducción del último año, los hogares españoles alcanzarán el nivel de la eurozona a mediados de 2018. Además, en un contexto de crecimiento del PIB y bajos tipos de interés, la reducción de la ratio de endeudamiento es compatible con flujos de crédito bancario positivos al sector. Por tanto, el exceso de deuda, que limitó el desempeño del sector privado al inicio de la recuperación, ya está dejando de ser una losa para el crecimiento (Gráfico 3).

\section{GRÁFICO 2}

DEUDA PRIVADA CONSOLIDADA

(En \% del PIB)

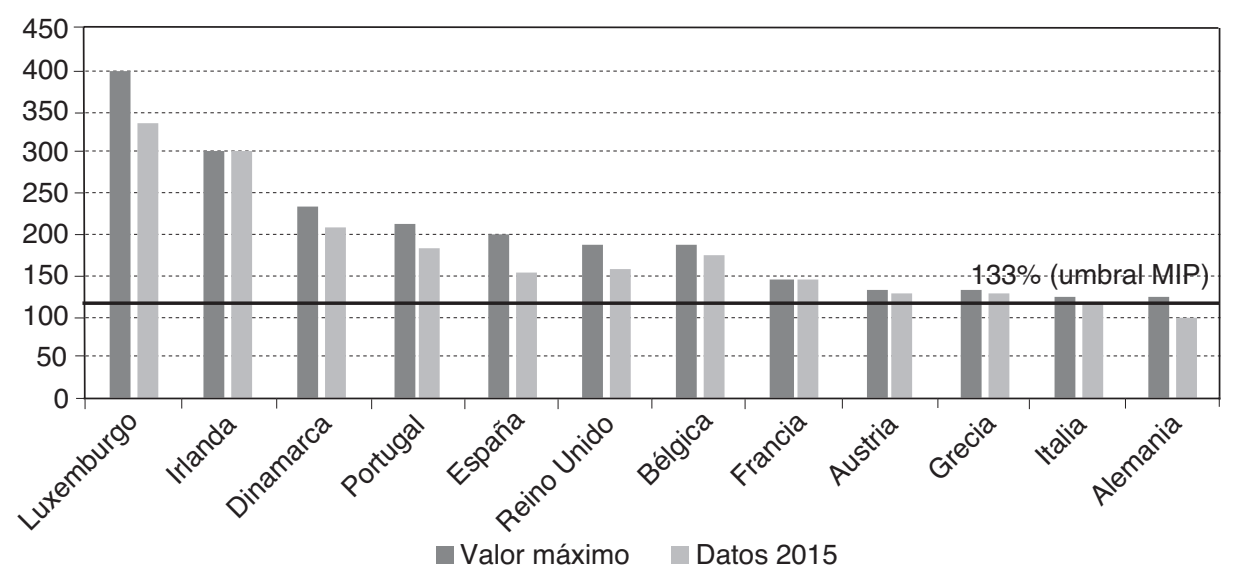

FUENTE: Eurostat. 


\section{GRÁFICO 3 \\ ESPAÑA Y EUROZONA: DEUDA DE HOGARES Y SOCIEDADES NO FINANCIERAS \\ (En \% del PIB)}

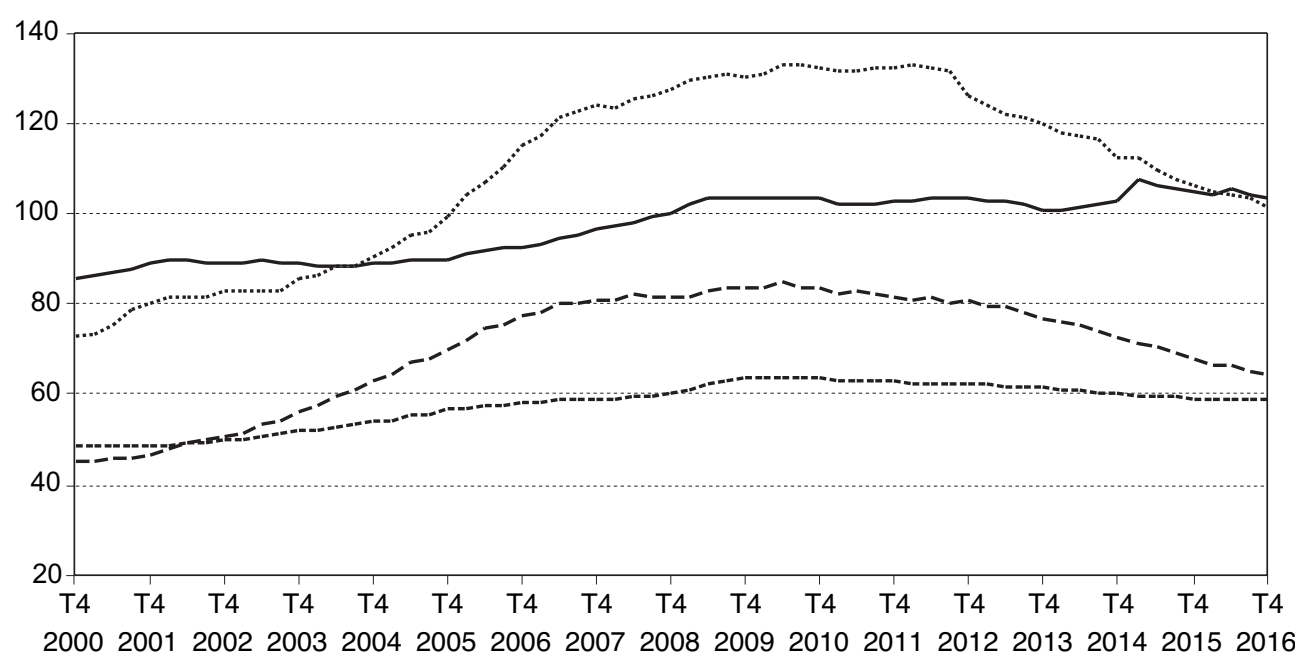

NOTA: Deuda no consolidada.

FUENTE: Banco de España y Eurostat.

Al contrario de lo que ocurre en el sector privado, la deuda pública todavía sigue creciendo aunque muestra signos de estabilización en porcentaje del PIB. Según el protocolo de déficit excesivo, esta se situó en el 99,4 por 100 del PIB al cierre de 2016 , solamente 0,4 p. p. por debajo del dato de 2015, y superando con creces el umbral del 60 por 100 establecido por la Comisión Europea. De hecho, el aumento de la deuda pública en los últimos 6 años, de 42,8 p. p., ha eclipsado el impacto del descenso de deuda privada en la deuda total. De cara a futuro, las proyecciones de los principales analistas y del propio gobierno apuntan a que la deuda pública, de cumplirse con la senda de reducción de déficit prevista, y gracias al mayor crecimiento del PIB nominal, irá descendiendo paulatinamente.

Actualmente, la suma de la deuda privada (sin consolidar) y la deuda pública todavía sigue siendo elevada, del 265,4 por 100 del PIB en el 4T 2016. Este nivel es solamente 9 p. p. inferior al del 2T 2010, cuando la deuda privada alcanzó su máximo. Sin embargo, la composición de la deuda total es muy distinta: si en 2010 el 80 por 100 de la deuda era privada, en 2016 este porcentaje se ha reducido al 75 por 100 . En contrapartida, la deuda pública ha ganado peso (Gráfico 4).

Por último, el sector de las instituciones financieras completa el total de la economía. Si a la deuda privada y la pública, le sumamos los valores representativos de deuda y los préstamos del pasivo del balance financiero de las instituciones 


\section{GRÁFICO 4 \\ DEUDA PÚBLICA Y DEUDA PRIVADA \\ (En \% del PIB)}

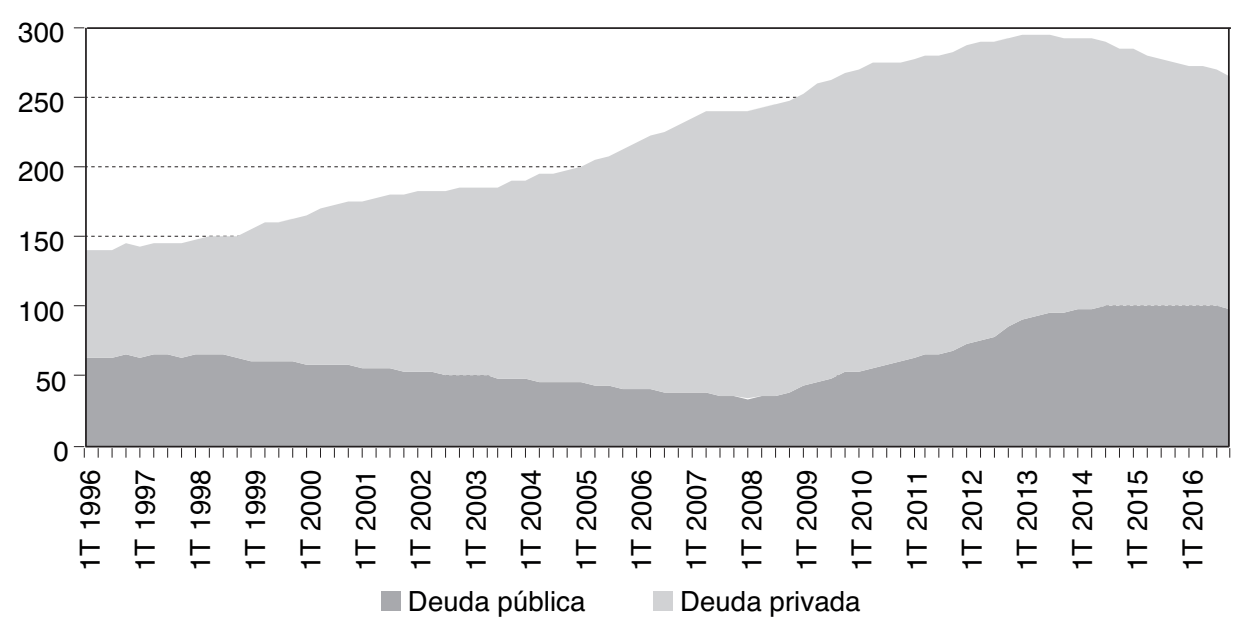

NOTA: Deuda pública PDE y deuda privada sin consolidar.

FUENTE: Banco de España.

financieras, la cifra de deuda total de la economía sin consolidar fue del 367,8 por 100 del PIB en el 4T 2016 (véase la primera columna del Gráfico 5). Si consolidamos la deuda dentro de cada sector, esta cifra desciende a 292,6 por 100 del PIB (véase la segunda columna del Gráfico 5). Sin embargo, como veremos en la sección 5, el endeudamiento de las instituciones financieras generalmente no se tiene en cuenta puesto que su función principal es la intermediación financiera y, por tanto, si se computase el total de su deuda se incurriría en una doble contabilización. En consecuencia, conviene ajustar el nivel de deuda bancaria y solo tener en cuenta la que no se destina a la financiación del resto de sectores residentes o, lo que es lo mismo, aquella contraída para financiar otras actividades como, por ejemplo, la compra de acciones de otras empresas (véase la tercera columna del Gráfico 5) ${ }^{5}$. Según este cálculo, la deuda ajustada del total de la economía era del 282,1 por 100 del PIB en el 4T 2016, mostrando un descenso de solamente 20 p. p. del PIB respecto al máximo de 2012 (Gráfico 6).

\footnotetext{
${ }^{5}$ De todos modos, es importante destacar que, desde la perspectiva de las instituciones financieras, la cifra de deuda total es la relevante a efectos de las obligaciones a las que tiene que responder el sector.
} 


\section{GRÁFICO 5 \\ DEUDA TOTAL Y POR SECTORES INSTITUCIONALES EN EL 4T 2016 (En \% del PIB)}

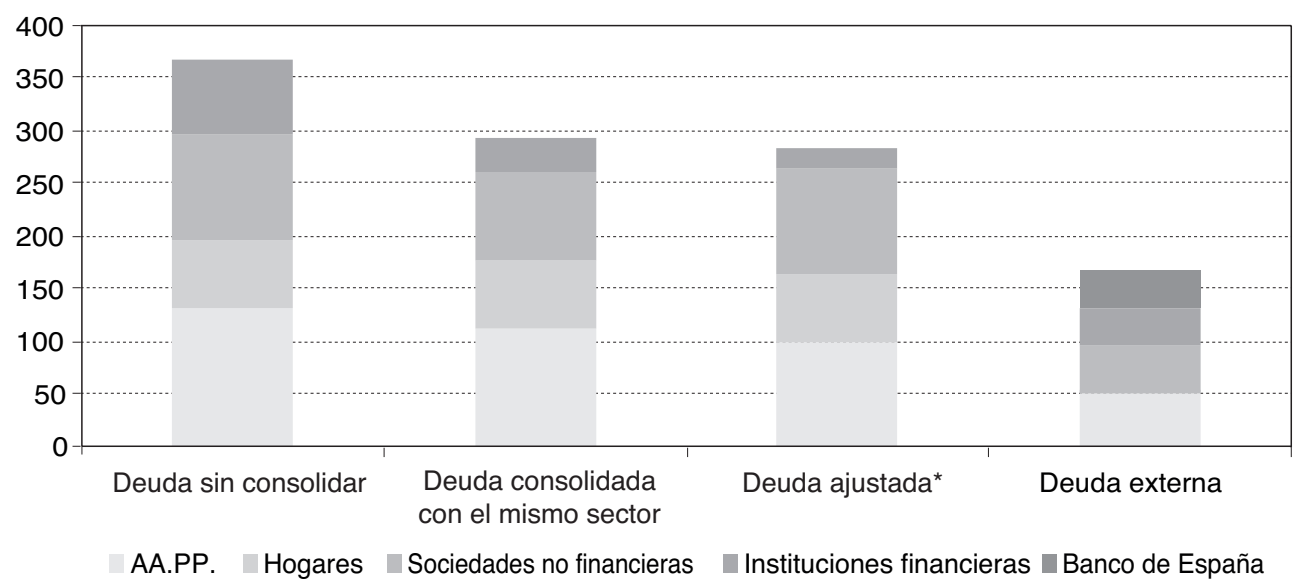

NOTA: Deuda de las instituciones financieras ajustada para evitar doble contabilización. En concreto, a los préstamos y títulos de deuda del pasivo de las instituciones financieras, se suman los depósitos del resto de mundo y los depósitos de residentes y se restan los préstamos y títulos de deuda de los residentes. Deuda pública PDE. Deuda de hogares y sociedades no financieras sin consolidar.

FUENTE: Banco de España.

\section{GRÁFICO 6}

\section{DEUDA TOTAL Y POR SECTORES INSTITUCIONALES* (En \% del PIB)}

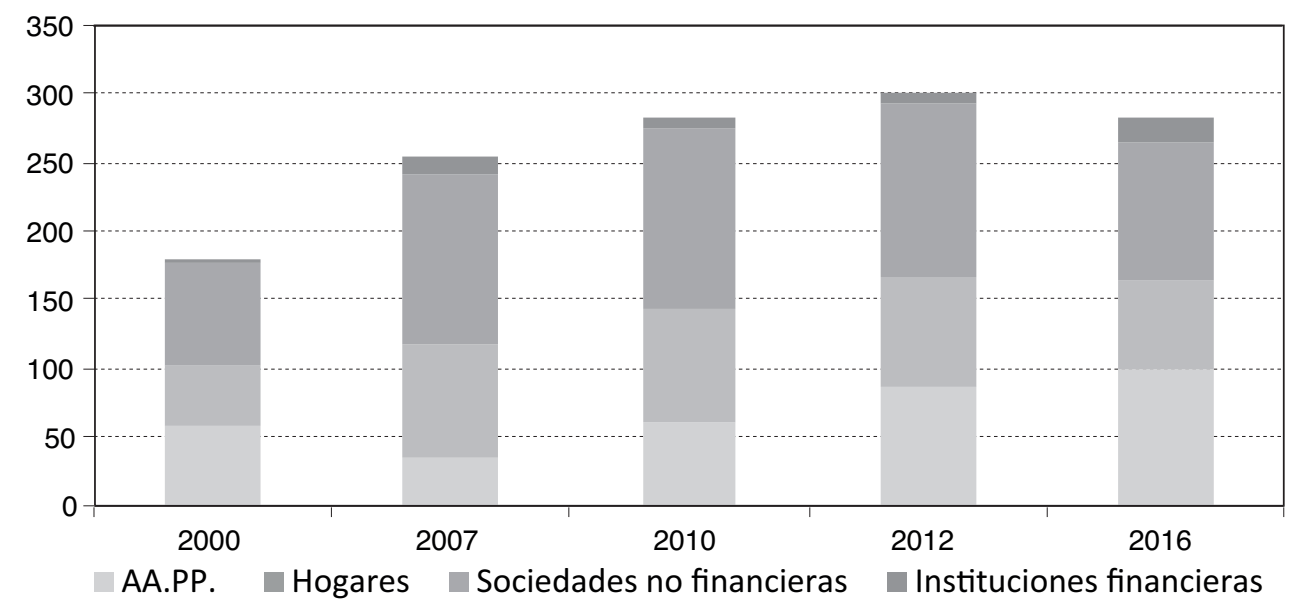

NOTA: Deuda pública PDE. Deuda de hogares y sociedades no financieras sin consolidar. Deuda de las instituciones financieras ajustada para evitar doble contabilización. En concreto, a los préstamos y títulos de deuda del pasivo de las instituciones financieras, se suman los depósitos del resto de mundo y los depósitos de residentes y se restan los préstamos y títulos de deuda de los residentes.

FUENTE: Banco de España. 


\section{La financiación de la deuda privada y pública: el papel del sector financiero y la dependencia de la financiación exterior}

En esta sección se analizan, para cada sector institucional, los instrumentos de deuda (préstamos o valores representativos de deuda) y el sector de contrapartida, con el fin de determinar el papel del sector bancario en la financiación de la deuda y la dependencia de la financiación exterior ${ }^{6}$.

Como se ha comentado anteriormente, durante la primera mitad de la década de los 2000, la deuda del sector privado creció notablemente. Dada la elevada bancarización de la economía española, este aumento de la deuda privada se correspondió con un aumento similar del crédito bancario ${ }^{7}$. En concreto, el flujo de crédito bancario al sector privado creció a un ritmo anual equivalente a 21,6 p. p. del PIB entre 2000 y 2007, por encima del umbral del 14 por 100 establecido por la Comisión Europea en el MIP.

Este espectacular crecimiento del crédito bancario se produjo también en otros países europeos, como Irlanda o Portugal, que también rebasaron el umbral del MIP. En 2008, sin embargo, los flujos de crédito al sector privado se ralentizaron en todos los países, especialmente en España, el país europeo con la mayor caída del flujo de crédito en promedio en el periodo 2008-2015 (Gráfico 7). De hecho, en España, el crédito bancario como proporción del PIB se ha reducido en 50,5 p. p. desde el máximo de 2010, con lo que ha superado la corrección que históricamente se ha observado en promedio después de crisis bancarias sistémicas, de 33 p. p., según las estimaciones de Aspachs et al. (2011) y, en la actualidad, se sitúa muy por debajo de su tendencia. Según estimaciones del Banco de España, la «brecha de crédito», definida como la diferencia entre ratio de crédito bancario sobre el PIB y su tendencia a largo plazo, se encuentra en territorio negativo, concretamente en el $-60,6$ por 100 del PIB en el 3T 2016. Esta cifra muestra la profundidad del proceso de desapalancamiento privado en España ${ }^{8}$.

En el caso de los hogares, la dependencia del sector bancario para financiarse es total. El análisis de su pasivo muestra que solamente un pequeño porcentaje de su deuda (alrededor del 0,2 por 100 en promedio) son préstamos obtenidos directamente del extranjero. El resto de la deuda es financiada por el sector financiero español (Gráfico 8).

${ }^{6}$ En este artículo analizamos el sector de las instituciones financieras en agregado. Véase BERGES y BALIÑA (2015) para un análisis similar en el que se diferencian las instituciones financieras monetarias de las no monetarias.

${ }^{7}$ Nótese que el crédito concedido por las instituciones financieras al sector privado es solamente una parte, aunque muy importante, de la deuda privada, ya que esta última incluye, además, el crédito concedido por otros sectores institucionales y otros valores de deuda, como bonos corporativos.

${ }^{8}$ Un valor bajo en este indicador también es indicativo de una baja probabilidad de que se produzca una crisis bancaria. Véanse BORIO y LOWE $(2002,2004)$. 


\section{GRÁFICO 7 \\ FLUJO DE CRÉDITO AL SECTOR PRIVADO (CONSOLIDADO) \\ (En \% del PIB)}

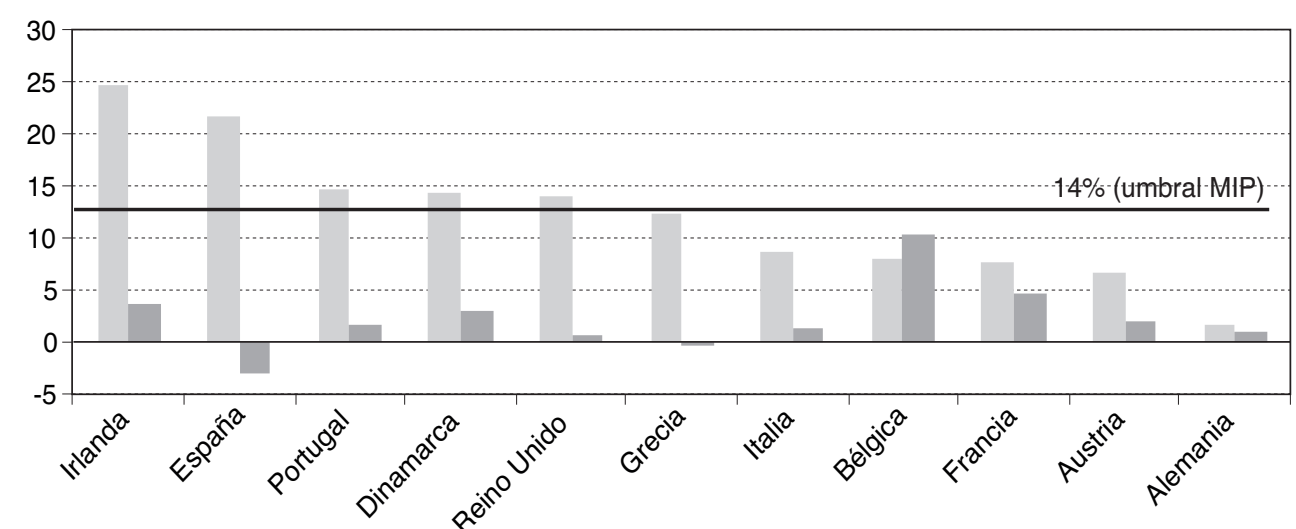

Promedio 2000-2007 — Promedio 2008-2015

FUENTE: Eurostat.

\section{GRÁFICO 8 \\ DEUDA EXTERNA POR SECTORES INSTITUCIONALES \\ (En \% del total de deuda consolidada de cada sector)}

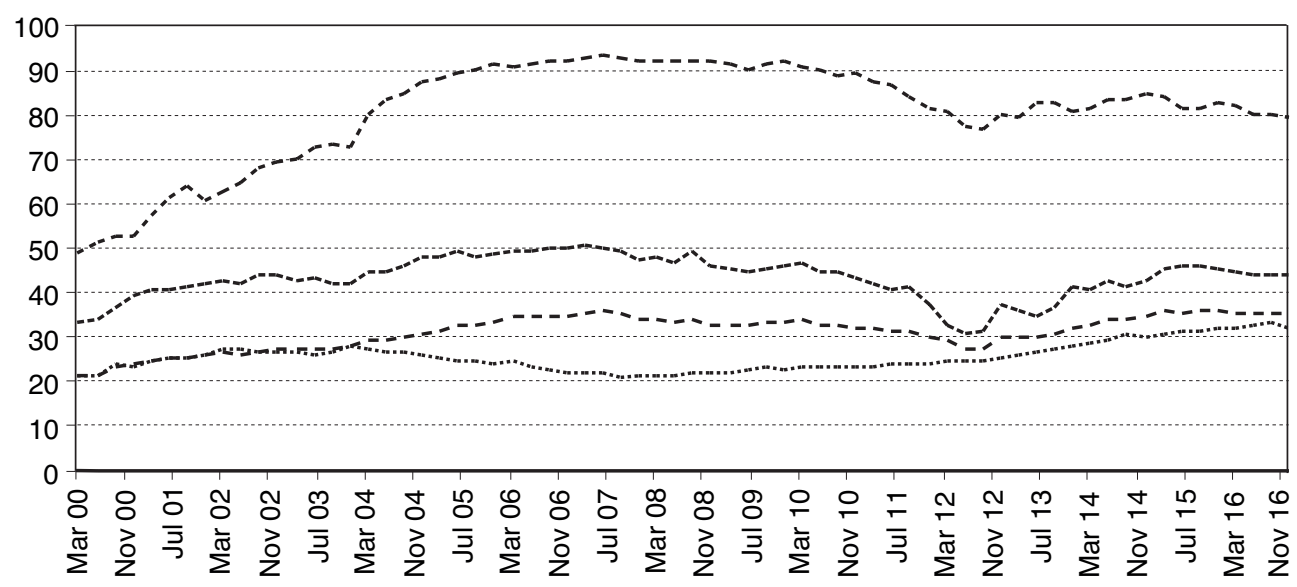

- Hogares (0-0)

- - - - Instituciones financieras - - - Total

FUENTE: Banco de España. 
Los instrumentos de deuda y contrapartidas en el caso de las sociedades no financieras es algo más complejo puesto que, además del crédito bancario, las empresas pueden recurrir a la emisión de valores representativos de deuda, como bonos corporativos. Es destacable que entre los años 2000 y 2007, el importe de estos valores en el pasivo de las sociedades no financieras se redujo de 15.920 a 12.747 millones de euros, y apenas representaban un 1 por 100 del total de deuda empresarial. De estos valores, solamente un 10 por 100 se encontraba en manos extranjeras en 2007 (1.315 millones). La apelación directa a los mercados financieros internacionales, por tanto, fue muy limitada durante la anterior etapa expansiva. A raíz de la crisis financiera de 2008 y el ajuste de balances que le siguió, el panorama ha cambiado sustancialmente: las empresas han aumentado la emisión de bonos y un elevado porcentaje de éstos se encuentra en manos de extranjeros. En concreto, el dato más reciente, del 4T 2016, muestra que las sociedades no financieras tienen en su balance unos 30.531 millones de euros en valores representativos de deuda y, de estos, un 35,7 por 100 tiene como contrapartida el resto del mundo.

En cuanto a los préstamos empresariales, que representan el 99 por 100 de la deuda de las sociedades no financieras, la apelación directa a la financiación exterior es más importante: alrededor de un 20 por 100 de los préstamos tenía como contrapartida el resto del mundo en 2007. Este porcentaje ha ido creciendo en la última década hasta situarse en el 32 por 100 en 2016. Así pues, teniendo en cuenta los bonos corporativos y los préstamos, alrededor de un tercio de la financiación de las empresas proviene directamente del resto del mundo.

Finalmente, hay que señalar que el sector público, donde la financiación exterior tiene el mayor peso, es el principal responsable de que la deuda externa no haya disminuido en los últimos años. En concreto, del aumento de la deuda pública de 63,8 p. p. del PIB entre 2007 y 2016, aproximadamente la mitad (32,2 p. p.) se encuentra en manos extranjeras (Gráfico 9). Como veremos con más detalle a continuación, en este mismo periodo, la dependencia de la financiación externa por parte de las instituciones financieras se ha reducido en una magnitud similar (-32,9 p. p.), de modo que la dependencia de la financiación externa del total de la economía española se ha mantenido prácticamente inalterada. 


\section{GRÁFICO 9 \\ DEUDA PÚBLICA: TOTAL Y EXTERNA \\ (En \% del PIB)}

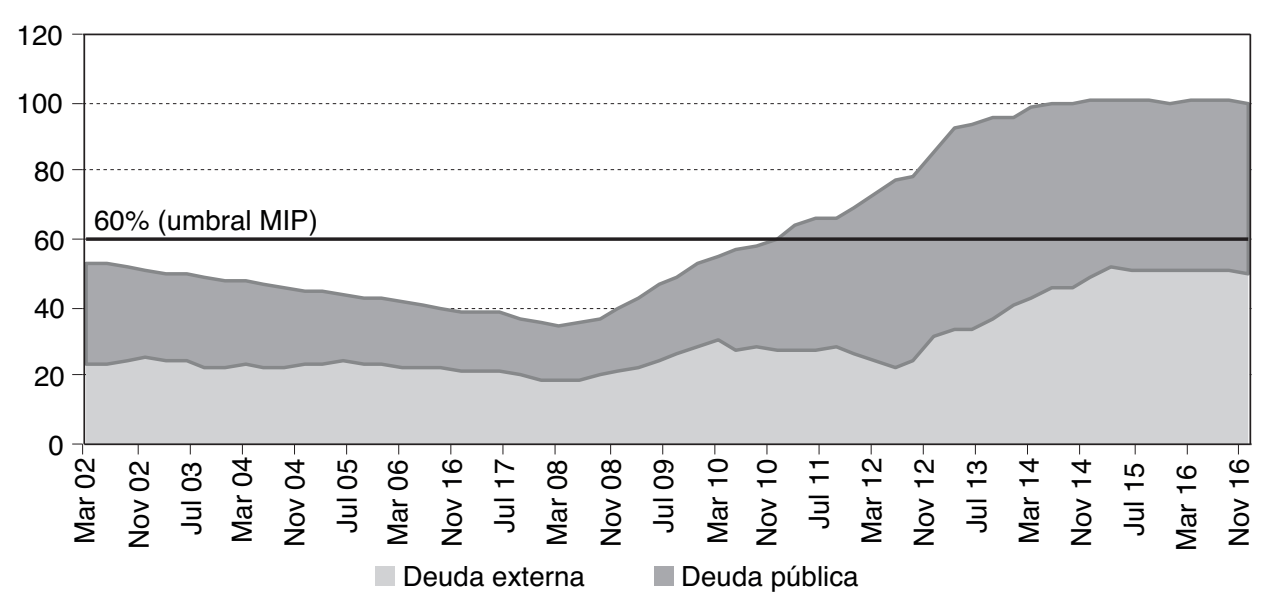

FUENTE: Banco de España.

\section{La evolución del balance financiero de las instituciones financieras}

Las dinámicas de endeudamiento y desendeudamiento del sector público y privado tienen su reflejo en los balances bancarios. En esta sección, a partir de los pasivos de las instituciones financieras, analizamos la evolución de las fuentes de financiación de la banca y su dependencia de la financiación externa.

Entre los años 2000 y 2007, las necesidades de financiación del sector privado crecieron notablemente. Dado que los depósitos de los residentes aumentaban a un menor ritmo, las instituciones financieras recurrieron a otras fuentes de financiación alternativas, en concreto, la emisión de deuda9 . Así, mientras que en el año 2000 los valores de deuda y préstamos emitidos por los bancos apenas representaban el 6,7 por 100 del PIB, estos aumentaron hasta el 66,7 por 100 del PIB en el 2T 2007 (aumento de 60 p. p.). La mayor parte de este incremento de la deuda bancaria fue adquirida por no residentes $(58,6$ p. p.) y el resto, muy marginal, los residentes $(1,4$ p. p.). Además, los depósitos de no residentes, que también se computan en la deuda externa ${ }^{10}$, también aumentaron en este periodo (4,5 p. p.). La financiación bancaria, por tanto, se volvió más dependiente de los flujos financieros provenientes del exterior.

No es de extrañar que en este periodo también se rebasara el umbral del MIP referente a la variación anual del total de pasivos del sector financiero, del 16,5 por

\footnotetext{
9 Véanse ÁLVAREZ (2008) y MAUDOS (2011).

10 Aunque la deuda incluye los préstamos y los valores representativos (pero no los depósitos), la deuda externa bruta sí incluye los depósitos de no residentes.
} 
100. En concreto, las instituciones financieras superaron este umbral en 2003, 2005, 2006 y 2007.

Gran parte de la deuda bancaria contraída entre los años 2000 y 2007 se destinó a la financiación del gap de intermediación financiera doméstica mencionado. En concreto, un 72 por 100 del total (47 p. p. del PIB) financió la concesión de crédito al sector residente que no se cubría con los depósitos de los residentes. El resto de la deuda contraída, equivalente a 13 p. p. del PIB, se usó para comprar otros activos financieros. En particular, destaca el aumento de la compra de activos emitidos por no residentes, tanto en forma de participaciones de capital como de valores de deuda (Gráfico 10).

Los flujos de capital del exterior son una fuente de financiación relativamente volátil y sensible a los cambios de percepción de riesgo por parte de los inversores. A partir de 2010, a raíz de las tensiones en los mercados de financiación bancaria mayorista provocados por la crisis de deuda soberana europea, una parte importante de la financiación bancaria proveniente del exterior se evaporó. En concreto, la deuda externa de las instituciones financieras españolas se redujo de forma abrupta, de 67,3 p. p. del PIB en 2009 a 47,6 en 2012. A partir de 2012, la dependencia de la financiación externa ha seguido reduciéndose, pero de forma más paulatina, hasta situarse en el 36,5 por 100 en 2016. Además, la mayor parte de los recursos bancarios se destinan a la intermediación financiera doméstica, apoyando así la recuperación de los flujos de crédito al sector privado. De todos modos, cabe destacar que el des-

\section{GRÁFICO 10}

\section{DEUDA DE LAS INSTITUCIONES FINANCIERAS POR FINALIDADES*} (En \% del PIB)

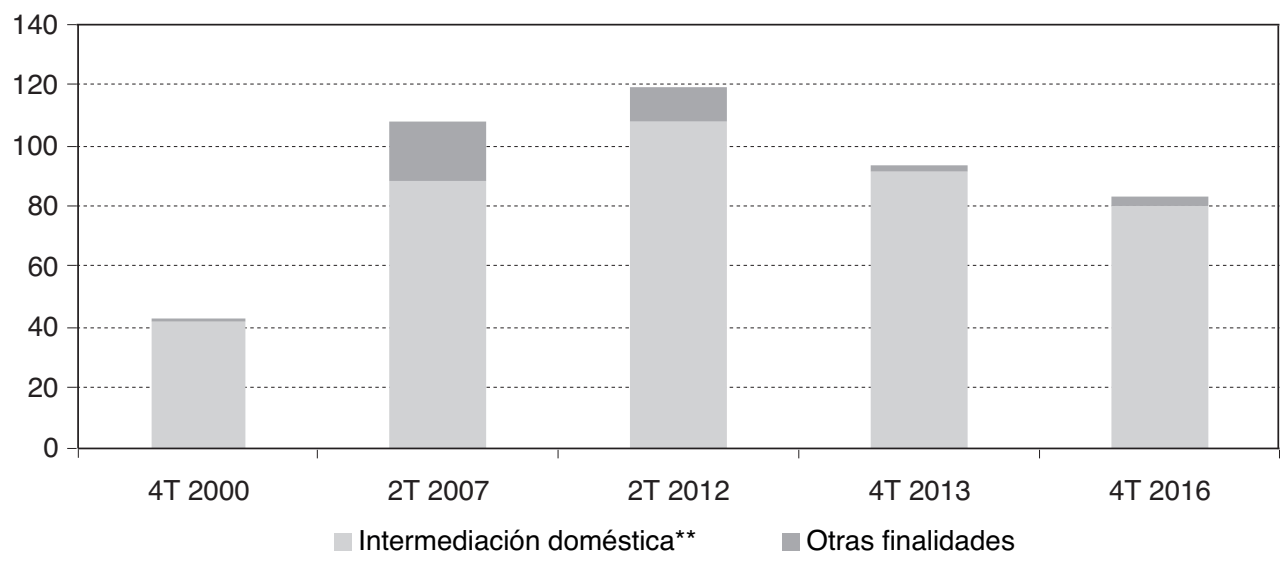

NOTAS: Deuda consolidada de las instituciones financieras (préstamos y valores de deuda en manos de residentes y del resto del mundo) más los depósitos del resto de mundo del pasivo de las instituciones financieras. Intermediación doméstica equivale a los préstamos y títulos de deuda de los residentes en el activo de las instituciones financieras menos los depósitos de residentes del pasivo.

FUENTE: Banco de España. 
endeudamiento del sector bancario respecto al resto del mundo ha sido sobradamente compensado por la financiación proveniente del Banco Central Europeo (BCE), que se canaliza a través del Banco de España (Gráfico 11), de modo que la dependencia externa de la economía española todavía sigue siendo elevada y muy dependiente de la política monetaria acomodaticia del BCE.

\section{GRÁFICO 11}

DEUDA EXTERNA DE LAS INSTITUCIONES FINANCIERAS

(En \% del PIB)

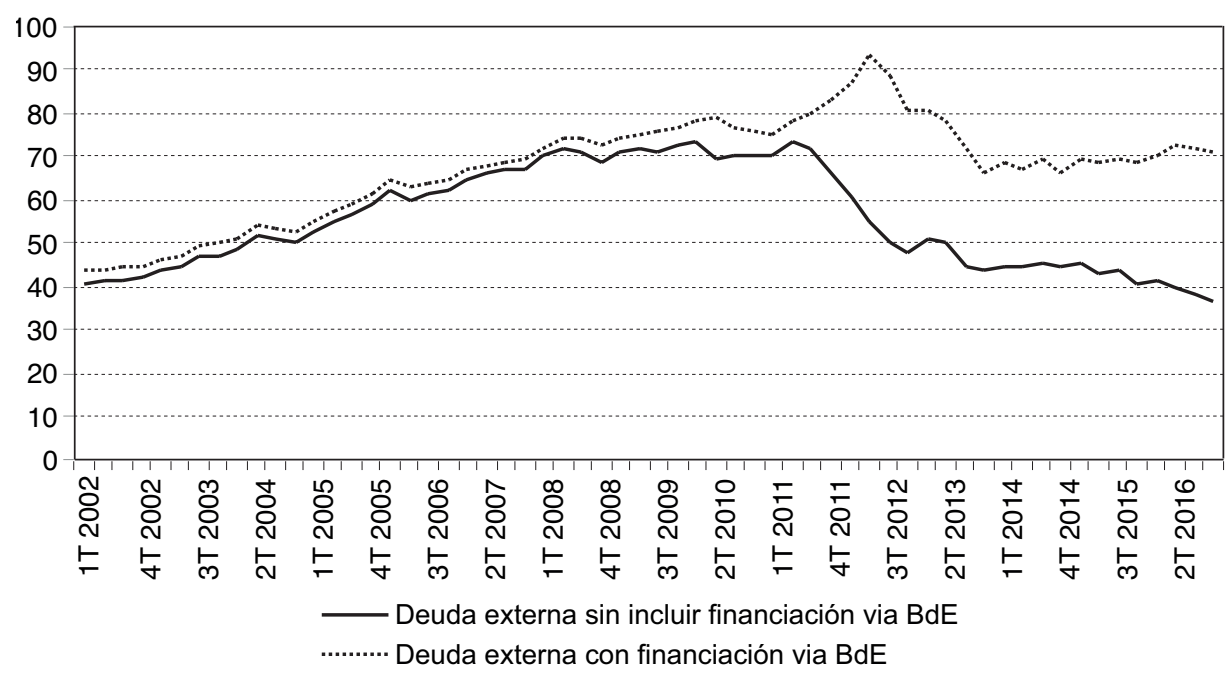

FUENTE: Banco de España

\section{Deuda externa y posición de inversión internacional neta del total de la economía}

En el 4T 2016, la deuda externa bruta del total de la economía representaba el 167,5 por 100 del PIB y, a diferencia de la deuda total, no muestra signos de descender. Como ya se ha comentado en la sección anterior, la composición sectorial de la deuda externa ha cambiado notablemente en los últimos años: parte de la deuda externa del sector financiero se ha reducido a través del desapalancamiento del sector y otra parte se ha desplazado al Banco de España, que canaliza el financiamiento externo procedente del BCE. Por otra parte, la menor deuda externa emitida por sociedades no financieras se ha visto más que contrarrestada por el aumento de la deuda pública externa (Gráfico 12).

En comparación con otros países europeos, la deuda externa de la economía española no es particularmente alta: si bien Alemania e Italia tienen una deuda 


\section{GRÁFICO 12 \\ DEUDA EXTERNA \\ (En \% del PIB)}

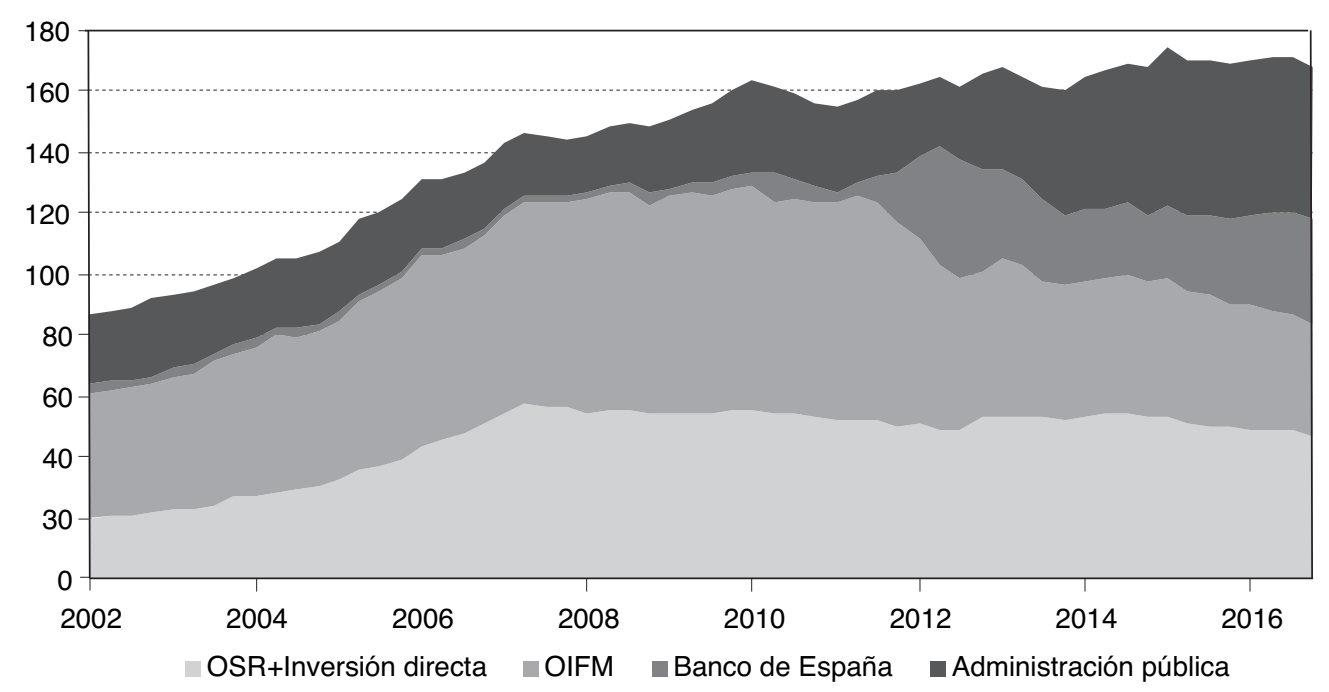

FUENTE: Banco de España.

inferior (medida en términos relativos al PIB), la mayor parte de países, como Austria, Portugal o Francia tienen una deuda externa bruta superior. Destaca especialmente Irlanda, con una deuda externa del 770 por 100 del PIB (Gráfico 13). No obstante, para valorar la posición deudora de una economía respecto al resto del mundo, es habitual usar la posición de inversión internacional neta (PIIN), que tiene en cuenta todos los pasivos de la economía española respecto al exterior (y no solamente los instrumentos de deuda) y, por otro lado, se consideran los activos que los residentes en España tienen en el exterior. De hecho, la variable PIIN es la medida escogida por la Comisión Europea para determinar la vulnerabilidad exterior de las economías europeas y, en el marco del mecanismo para evaluar los desequilibrios macroeconómicos (MIP), estableció un umbral del -35 por 100. En el 4T 2016, la posición neta de España fue del $-85,7$ por 100 del PIB, un nivel relativamente alto en comparación con otras economías europeas (gráfico 14). No obstante, en los últimos tres trimestres, ha mejorado como resultado del superávit por cuenta corriente que, de mantenerse, deberían mejorar aún más la posición de pasivo neto en el medio plazo. De todos modos, es necesario mantener un superávit corriente sostenido durante más de una década para reducir la PIIN hasta el umbral del -35 por 100 establecido por la Comisión ${ }^{11}$.

\footnotetext{
11 Véase MELIVEO y MONTORIOL (2016).
} 


\section{GRÁFICO 13 \\ DEUDA EXTERNA BRUTA \\ (En \% del PIB)}

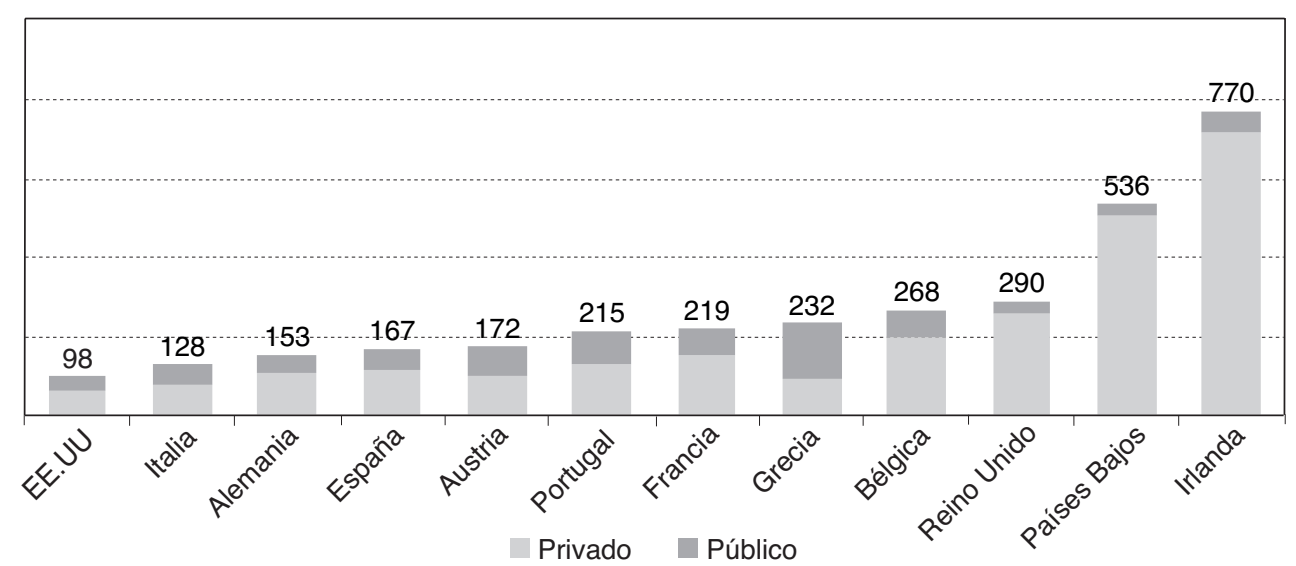

NOTA: Datos del 3T 2016.

FUENTE: Banco de España y Datastream.
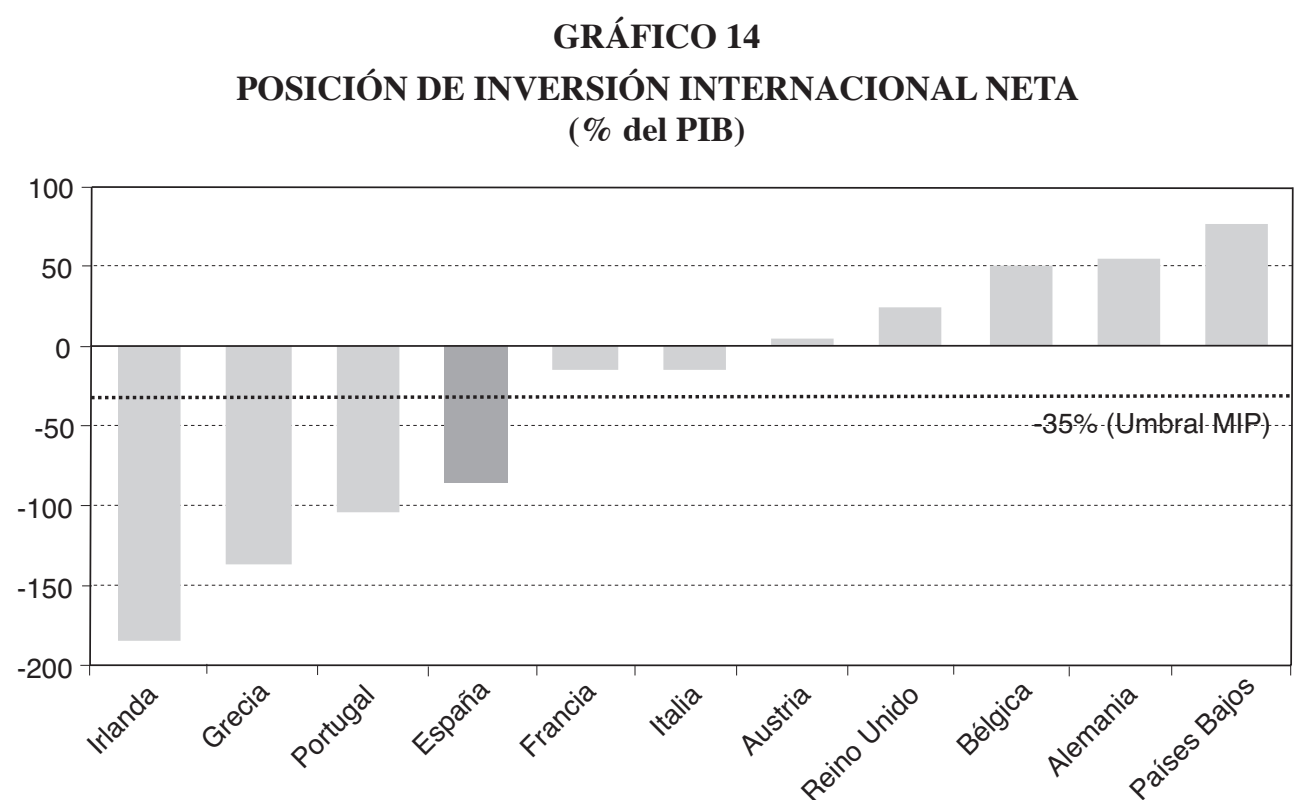

NOTA: Datos del 4T 2016.

FUENTE: Eurostat. 


\section{Conclusión}

La economía española ha empezado a desendeudarse en los últimos años cuando se evalúa de forma conjunta, pero lo ha hecho de forma muy desigual entre sectores. En el 4T 2016 la deuda total representaba el 282 por 100 del PIB, lo que suponía estar solamente 20 p. p. por debajo del máximo de 2012 (302 por 100 del PIB). Además, gran parte de los préstamos y títulos de deuda se encuentran en manos de no residentes, de modo que la economía sigue siendo vulnerable a potenciales cambios en las percepciones y expectativas de los inversores internacionales. Concretamente, en el 4T 2016, la deuda externa representaba el 167,5 por 100 del PIB y, a diferencia de la deuda total, no muestra signos de descender. Por un lado, las instituciones financieras han reducido su dependencia directa del exterior, pero ello se ha prácticamente compensado por un aumento de la deuda externa del Banco de España que canaliza la financiación del Eurosistema hacia el sector bancario español. Por otro lado, la deuda pública externa ha aumentado rápidamente: de los 18,7 p. p. en 2007 a los 49,6 p. p. en 2016.

En definitiva, la economía española todavía está muy endeudada, en especial con el exterior. El desendeudamiento del sector privado español ha sido muy intenso, tanto si se compara con el que han llevado a cabo otras economías europeas durante este mismo episodio como, históricamente, en relación con otras crisis bancarias. Por tanto, el proceso de desapalancamiento del sector privado ya está casi completado. En los próximos trimestres, a diferencia de lo ocurrido en los últimos 6 años, el desendeudamiento pendiente del sector privado será compatible con un flujo positivo de crédito hacia las empresas y las familias, lo que impulsará el crecimiento. Ahora que los vientos soplan de cola, el sector público también debería encauzar el mismo camino para así reducir la fuerte dependencia de la economía española de la financiación externa.

\section{Referencias bibliográficas}

[1] ÁLVAREZ, J. A. (2008). «La banca española ante la actual crisis financiera». Revista de Estabilidad Financiera, 38, noviembre.

[2] ASPACHS, O.; GUAL, J. y JÓDAR, S. (2011). «Perspectivas de desapalancamiento en España». Documentos de Economía de la Caixa, 23.

[3] AVDJIEV, S.; MCCAULEY, R. y MCGUIRE, P. (2012). «Rapid credit growth and international credit: challenges for Asia». BIS Working Papers, 377.

[4] BERGES, A. y BALIÑA, S. (2015). «El mapa de la deuda en España: ¿quién debe a quién?». Cuadernos de Información Económica, 244.

[5] BORIO, C. y LOWE, P. (2002). «Assessing the risk of banking crisis». BIS Quarterly Review, 43-54.

[6] BORIO, C. y LOWE, P. (2004). «Securing sustainable price stability: should credit come back from the wilderness?». BIS Working Papers, 157. 
[7] BORIO, C.; MCCAULEY, R. y MCGUIRE, P. (2011). «Global credit and domestic credit booms». BIS Quarterly Review, 43-57.

[8] COMISIÓN EUROPEA (2012). «Scoreboard for the surveillance of macroeconomic imbalances». Occasional Papers, 92.

[9] MAUDOS, J. (2011). El sector bancario español en el contexto internacional: el impacto de la crisis. Fundación de las Cajas de Ahorros.

[10] MELIVEO, J. y MONTORIOL, J. (2016). «La posición externa de la economía española: claves para reducirla». Documento de Trabajo 02/16, CaixaBank Research. 